\title{
Damage mechanism of wind turbine blade under the impact of lightning induced arcs
}

\author{
Minhao Zhang ${ }^{1}$, Qingmin $\mathrm{Li}^{1}$, Hongbo $\mathrm{Li}^{1}$, Wanshui $\mathrm{Yu}^{1}$, Zixin Guo ${ }^{1}$, Wah Hoon Siew ${ }^{2}$ \\ 1. State Key Laboratory of Alternate Electrical Power System with Renewable Energy Sources, North China Electric \\ Power University, Beijing 102206, China; \\ 2. Department of Electric \& Electronic Engineering, University of Strathclyde, Glasgow G1 1XQ UK.
}

\begin{abstract}
:
It is not clear for the damage mechanism of the blade structure under the effect of the lightning strike arc. In this paper, the damage characteristics of blades under the effect of lightning arc are obtained by the impulse large current experiment. Based on the actual blade structure, An MHD (magnetohydrodynamics) model is built suitable for multi-field coupling of heat-magnetic-airflow and we obtain the temporal and spatial variation of the temperature and pressure. The experimental results show that the blade tends to crack from the position of the trailing edge near the arc attachment point and the crack extends in the direction of the blade root and tip. The length of carbonization damage caused by high temperature of arc is much smaller than the crack length due to the airflow impact. When the down-conductor is placed on the main beam, carbonization damage distributes in the area between the left web and the trailing edge. When placed on the right web, it distributes between the right web and the trailing edge. In the finite element simulation, the temperature of the arc ignited point increases to the peak value and then decreases rapidly and then, it increases to the maximum and tend to stabilize. The high temperature inside the blade region diffuses from the boundary between the pressure surface and the right web to the trailing edge. The pressure of trailing edge increases to the maximum and then oscillates to decrease. The airflow inside the blade continuously oscillates between the right web and the trailing edge. It is recommended to improve the toughness of epoxy resin adhesive and set the down-conductor on the main beam.
\end{abstract}

Key words: Wind turbine blade, lightning protection, impulse current experiment, damage mechanism,

\section{Introduction}

With the rapid development of the wind power generation [1], the lightning protection of wind turbines has become a major technical problem that needs to be solved urgently. In many accidents caused by lightning, the blade has become the main lightning strike attachment point due to its huge height [2]. Once suffering lightning strikes, the blade might be damaged, which will bring huge economic losses. The existing wind turbine blade lightning protection system (receptor and down-conductor system) can prevent lightning damage to a certain extent, and related research mainly focuses on the optimal design of the lightning receptor. In the Ref. 3, the authors respectively place two types of receptors on the blades. The first is to place copper circular with a diameter of $25 \mathrm{~mm}$ at the location where is $250 \mathrm{~mm}$ away from the blade tip and $130 \mathrm{~mm}$ away from the leading and trailing edge. The second is to wrap the blade tip in copper. It is found that the lightning protection effect of the second type is better, but sometimes the failure will occur under the positive lightning. In the Ref. 4, the authors find that the metal components in the blade (such as sensors) will reduce the rate of successful attachment, and they propose a design principle of the receptor considering the influence of the metal components. But no specific solution is proposed. In the Ref. 5 , the authors find that in the marine environment, when the salt fog is attached to the surface of the blade, the probability of being struck by lightning increases. The closer the salt fog is to the receptor, the greater the lightning strike probability is. Furthermore, it is proposed that advanced marine antifouling coatings should be applied on the surface of the receptor to increase the lightning protection capability. In the Ref. 6, the authors find that the curvature of the receptor affects the lightning strike triggering ability of the blade. The lightning protection effect will be better if the curvature of receptor is smaller. However, the lightning receptor with a small curvature still cannot achieve complete protection against lightning strikes. None of above research can achieve complete protection from lightning strikes. Therefore, consideration should be given to study the mechanism of blade damage under the impact of lightning arc and strengthen the blade's ability to withstand lightning strike.

Vestas company conduct a two-year lightning strike observation on two hundred and thirty-six blades with a length of $39 \mathrm{~m}$, and they find that $88 \%$ of lightning strikes locate within $1 \mathrm{~m}$ from the blade tip, and the rest $12 \%$ locate within $5 \mathrm{~m}$ from the blade tip [7]. When the lightning strikes blade, current will pass through the blade surface, burning the material near the arc. Toshio Ogasawara et al. pointed out that the Joule heat caused by lightning current can bring thermal decomposition of epoxy resin and gasification of fiber materials, resulting in delamination of material [8]. Zhang et al. studied the pyrolysis reaction process of blade material under the effect of high temperature and analyzed the variation of its polymer degree [9]. Many studies on the damage of blade material have been carried out [10-13]. However, the lightning current transmitting along the internal path of the blade will cause a high-temperature arc and high-pressure shock waves, causing structural damage to the blade [14]. Relevant research on this part is relatively scarce. In Ref.15, The distribution of pressure in the closed cavity under impulse current was tested. However, above studies cannot obtain the characteristics of the structural damage, which fail to reveal the damage mechanism caused by the lightning arc. 
Injecting a large impulse current into the actual blade can provide the most direct method for studying the effect of the lightning arc inside the blade. However, when the blade is struck by lightning, the structural damage caused by the high temperature and pressure is a high-speed dynamic process. It is difficult to observe the damage details and measure relevant parameters by traditional experimental methods. Therefore, it is necessary to use simulation methods to reveal the damage mechanism of the blade structure. Wei et al. established an axisymmetric model and used finite element simulation software to calculate the distribution of ambient temperature field during the fall of the pantograph arc based on the MHD theory [16]. The basic equations in their model provide reference for this paper, but the blade calculation area is two orders of magnitude larger than the arc area of Wei's model. Hence, the vector magnetic position method is replaced by the Biot-Savart law for calculating the electromagnetic field. Zou et al. studied the distribution characteristics of high-temperature plasma generated by parallel double-wire electric explosion in vacuum [17], which provides a reference for the physical properties of the arc plasma. Rong et al. used MHD to study the internal fault arc in a closed vessel and simulate the arc-extinguishing process between the two rod electrodes in the air under the action of AC current [18]. Their research subjects have good symmetry, but the internal section of the blade is an asymmetrical structure and has a sharp region. Therefore, special treatment is required for these areas. Yan et al. studied the breaking arc of the circuit breaker and pointed out that the arc column would not cause significant distortion to the magnetic field at high or low current [19]. Accordingly, this paper does not consider the distortion effect of the lightning arc column on the internal magnetic field of the blade. Sun et al. pointed out that the length of the arc was not related to the magnitude of the current [20]. The above research progress on arc plasma can provide a valuable reference for studying the lightning arc in the blade and exploring the force characteristics of the blade chamber. However, most of the above studies are based on the study of symmetrical models. The blade structure is asymmetric. In addition, the lightning arc has a typical arc path and instantaneous impact effect, which is more difficult to calculate. Therefore, it is necessary to simplify according to its geometry and computational complexity to improve computational efficiency.

By investigating the lightning strike data of wind farms, the arc path of the experiment is determined. Then we compare the structural damage of the blade under the impact of large impulse current for different arc ignited positions and arc paths. Furthermore, based on the MHD theory, the damage mechanism of the blade is studied. COMSOL is used to calculate the internal temperature and pressure distribution of the blade chamber. The simulation results have a good correspondence with the experimental results.

\section{Experimental study on blade structure damage under large impulse current}

\subsection{Experimental set}

The geometry structure of an actual blade is shown in Fig. 1. It consists of a pressure surface (PS surface) and a suction surface (SS surface). Two webs support the blade structure, and the down-conductor guides the lightning current to the ground. The typical paths of lightning strike arc are shown in Fig. 2. The main beam (the middle green part of Fig. 2) and the trailing edge joint (the right green side of Fig. 2) are made of epoxy resin. The rest (the yellow part of Fig. 2) uses sandwich material. The round red point indicates the down-conductor. The lightning strike point of the actual blade is generally located within $5 \mathrm{~m}$ from the tip of the blade. Most lightning strike arcs have three typical paths inside the blade: (1) The lightning strike arc enters from the center right of the PS surface, connects to the down-conductor on the web, as shown in Fig. 2(a). (2) The lightning strike arc enters from the center right of the PS surface, penetrates the right web, and connects with the down-conductor on the main beam, as shown in Fig. 2(b). (3) The web plays a supporting role inside the blade. At the position close to the tip of the blade, the space is narrow and does not need support, so the web disappears. The lightning strike arc enters from the center right of the PS surface, and then connects with the downconductor on the main beam, as shown in Fig. 2(c).

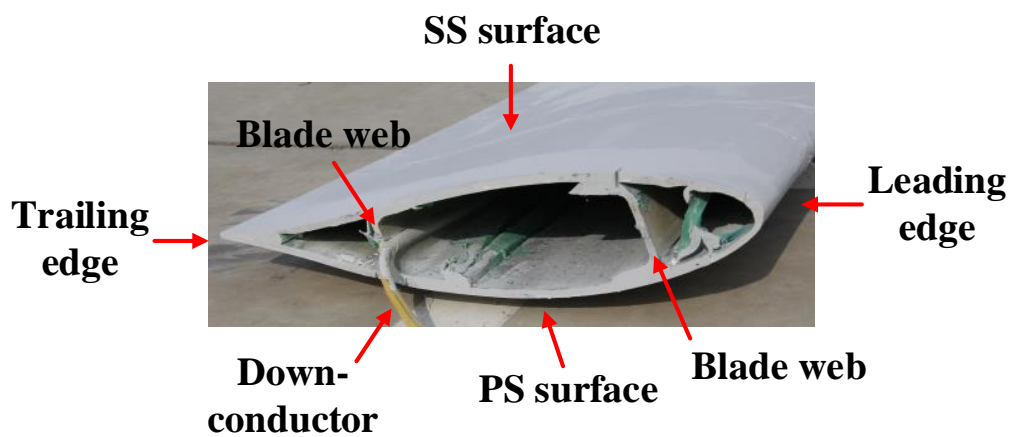

Fig. 1 cross section of an actual blade 


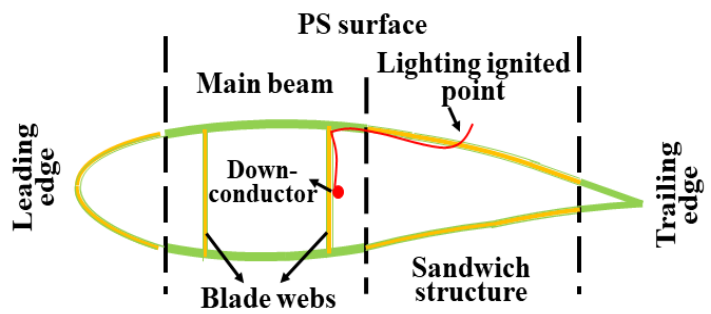

SS surface

(a) typical path I

PS surface

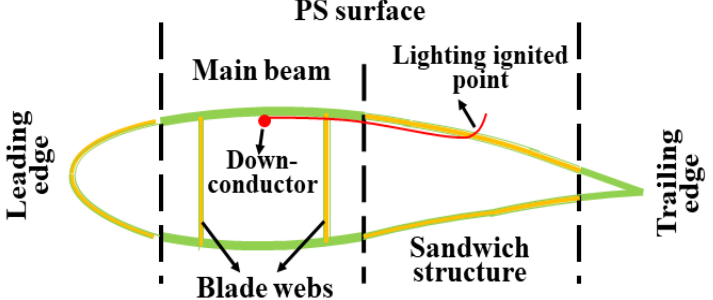

SS surface

(b) typical path II

PS surface

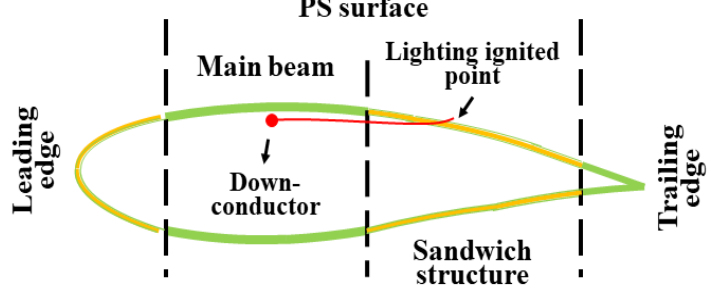

SS surface

(c) typical path III

Fig. 2 Typical path of lightning strike arc

According to above research results, the experimental scheme is determined as follows: The lightning strike point of the actual blade is generally located the area within $5 \mathrm{~m}$ from the tip of the blade. Hence, three 5-meters-long blades are adopted as experimental specimen, as shown in Fig. 3. A nickel-chromium wire with a diameter of $0.1 \mathrm{~mm}$ is used to induce the arc. For the first blade, the arc ignited point is located $3 \mathrm{~m}$ away from the tip of the blade. The arc path is shown by the red line in Fig. 2(a). For the second blade, the arc ignited point is located $2 \mathrm{~m}$ away from the tip of the blade. The arc path is shown by the red line in Fig. 2(b). For the third blade, the arc ignited point is located $1 \mathrm{~m}$ away from the tip of the blade. The arc path is shown by the red line in Fig. 2(c). In the experiment, the impulse current generator is used to generate a negative impulse current with peak value of $150 \mathrm{kA}$ and time duration of $25 \mu \mathrm{s} / 250 \mu \mathrm{s}$. The experimental platform is shown in Fig. 4.

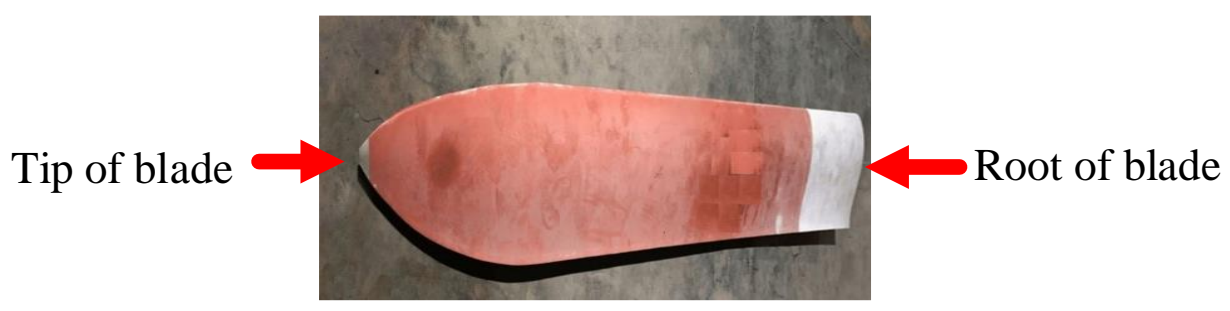

Fig. $35 \mathrm{~m}$ long specimen cut from the real blade. 


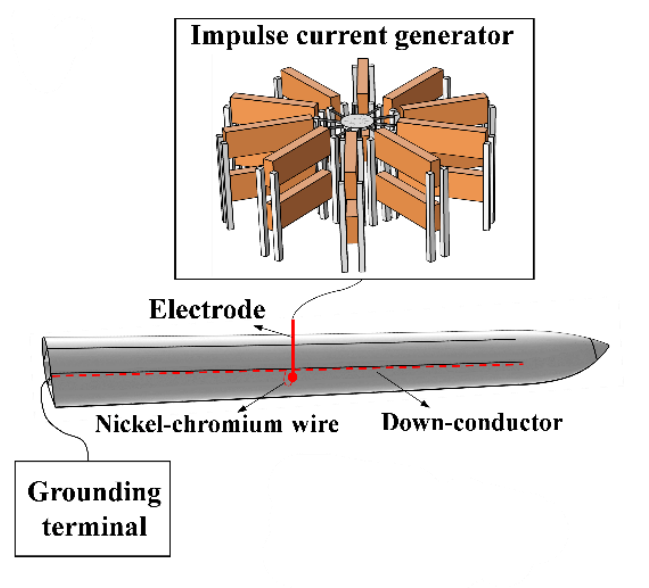

Fig. 4 Experiment platform

\subsection{Experimental results}

The damage position of the blade is shown in Fig. 5. The location of carbonation damage is near the arc ignited point, and the structural crack damage is near the trailing edge. The two types of damage are shown in Fig. 6, the left picture represents carbonization damage, and right picture represents crack damage. When the down-conductor is placed on the main beam, carbonization damage distributes in the area between the left web and the trailing edge, which is shown in Fig. 7(a). When placed on the right web, it distributes between the right web and the trailing edge, which is shown in Fig. 7(b). The main experimental results are shown in Fig. 8. The damage caused by large impulse current on the blade are mainly material carbonization and structural crack. The " 0 " in Fig. 8 represents the arc ignited point. In Fig. 8, the black line represents the material carbonization length, and the red line represents the structure crack length. It can be seen from the Fig. 8 that the carbonization damage is lighter than the structural crack damage.

When the arc ignited point is $3 \mathrm{~m}$ away from the tip of the blade, the space in the blade chamber near the arc ignited point is ample. Therefore, the airflow is less affected by blade structure. The crack damage takes the arc ignited point as the midpoint, and the crack length on both sides of the arc ignited point are not much different. The right web of the blade just partially carbonizes and not cracks. However, when the arc ignited point is $2 \mathrm{~m}$ away from the tip of the blade, the blade width in the direction of the tip sharply reduces and the space is narrow. The trailing edge is prone to burst under the effect of impulse airflow caused by the induced arc. The crack size in the direction of the tip of the blade is larger than the direction of the root. At this time, the right web of the blade has burst, but the left web is not damaged. When the arc ignited point is $1 \mathrm{~m}$ away from the tip of the blade, the damage extends to the tip, and the material of the junction between the receptor and the skin is torn.

The damage on the blade under the effect of the lightning arc is a dynamic process. It is difficult to reproduce all possible damage process and detail by traditional experiment methods, and actual blades used in the experiment is expensive. Therefore, it is necessary to build model and carry out simulation based on experimental results to reveal the mechanism of blade damage.

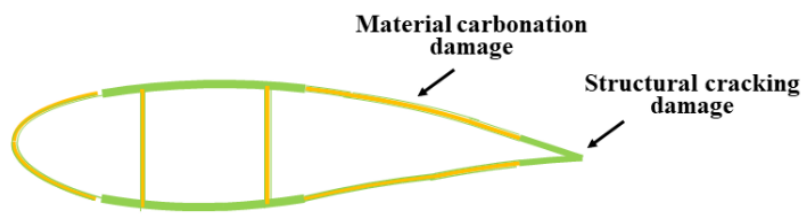

Fig. 5 The location of blade damage cause by large impulse current in the experiment 


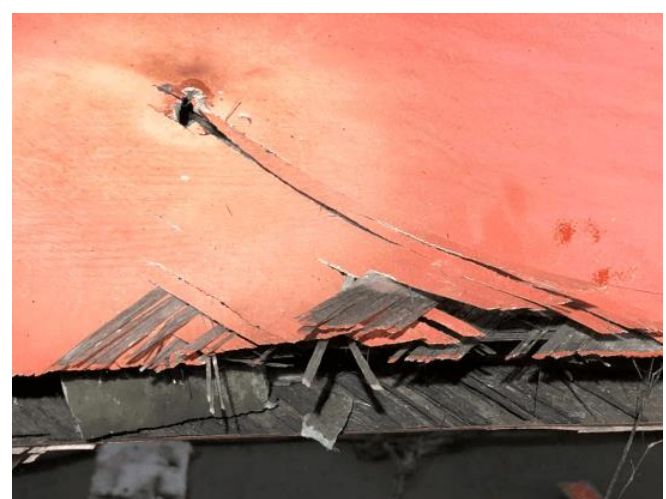

(a) carbonization damage

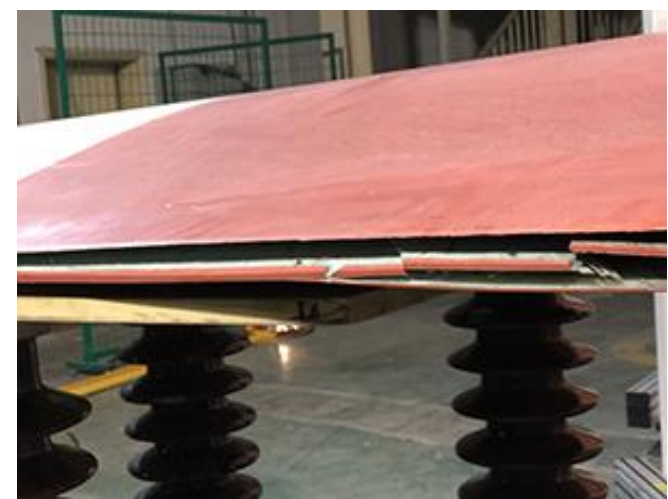

(b) crack damage

Fig. 6 Typical damage features of the test blades under large impulse current

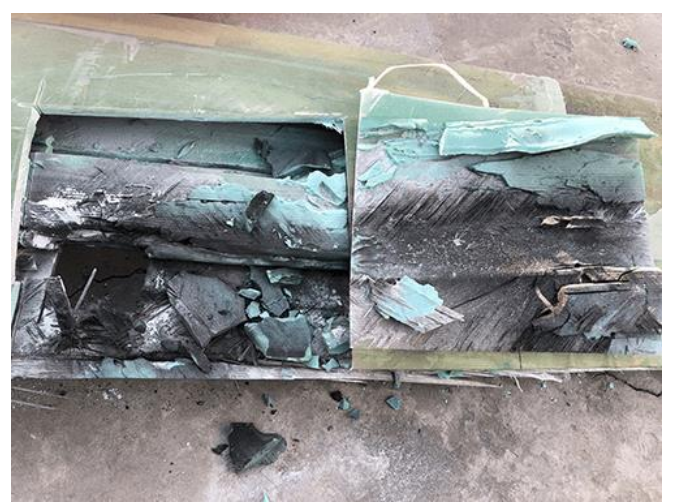

(a) arc path I

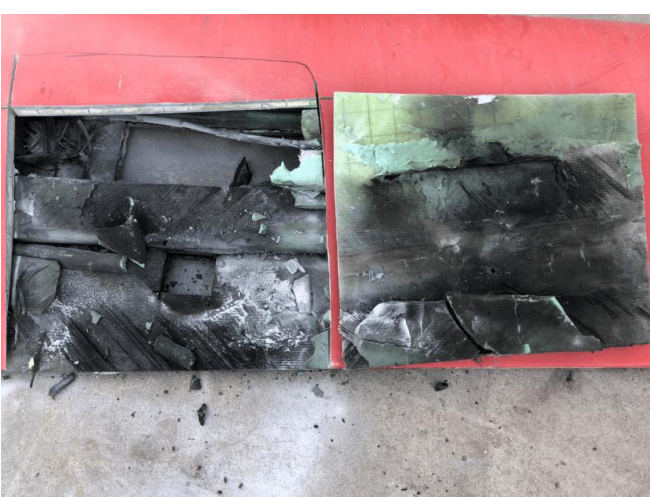

(b) arc path II

Fig. 7 Inside damage of the blade with different arc paths

Arc ignited position
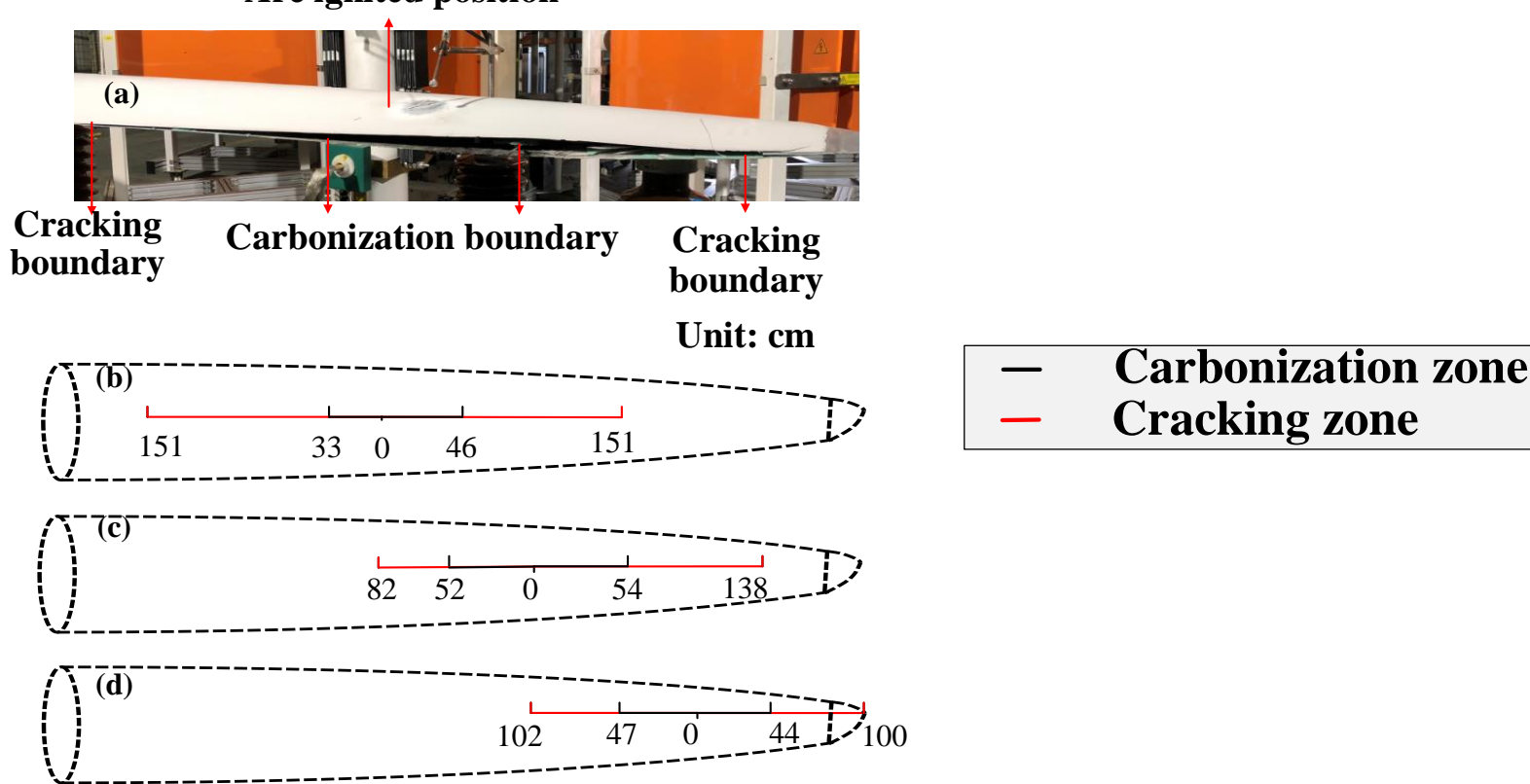

Fig. 8 The length of material carbonization and structure crack

3. Modeling of the coupling of thermal, airflow fields and electromagnetic

In this paper, the MHD theory is used to establish the lightning arc model and analyze the damage characteristics. 3.1 Fluid dynamics equations

Equations (1)-(3) are the continuity equation, the momentum conservation equation and the energy conservation equation. 


$$
\begin{gathered}
\frac{\partial \rho}{\partial t}+\nabla \cdot(\rho \mathbf{u})=0, \\
\frac{\partial p \mathbf{u}}{\partial t}+\rho(\nabla \cdot \mathbf{u}) \mathbf{u}=-\nabla p+\nabla \cdot\left[\mu\left(\nabla \mathbf{u}+(\nabla \mathbf{u})^{\mathrm{T}}\right)-\frac{2}{3} \mu(\nabla \cdot \mathbf{u}) \mathbf{A}\right]+\rho \mathbf{g}+\mathbf{J} \times \mathbf{B}, \\
\frac{\partial\left(\rho C_{p} T\right)}{\partial t}+\nabla \cdot\left(\rho C_{p} T \mathbf{u}\right)=\nabla \cdot(k \nabla T)+\sigma E^{2}+q_{r a d}+q_{\eta}, \\
q_{r a d}=4 \alpha k\left(T^{4}-T_{0}^{4}\right),
\end{gathered}
$$

Where, $\rho$ is the fluid density, $p$ is the pressure, $T$ is the temperature, $u$ is the fluid velocity, $R_{\mathrm{S}}$ is the constant, $\mu$ is the dynamic viscosity, $g$ is the gravity acceleration, $C_{\mathrm{p}}$ is the fluid constant pressure heat capacity, $k$ is the thermal conductivity, $q_{\text {rad }}$ is radiant heat, $q_{\mathrm{n}}$ is referred to viscous heat.

In the equation (2) momentum conservation equation, the Lorentz force of the arc plasma in the magnetic field is taken into consideration. Since the plasma particle mass is very light, the influence of gravity is ignored and $\rho \mathbf{g}$ is equal to 0 . In the energy conservation equation, the Joule heat of the arc is equal to $\sigma E^{2}$. Since the viscous dissipation term does not generate extra heat in the energy conservation equation, $q_{n}$ is equal to 0 .

For the thermal radiation term $q_{r a d}$, it is determined by the simplified equation (4) [21], where $\alpha$ is the Boltzmann constant, $k$ is the absorption coefficient, $T$ is the arc temperature, and $T_{0}$ is the environment temperature.

\subsection{Lightning arc geometry model}

Based on the experimental results shown in the second paragraph of Section 2.2, the geometry model used for the simulation is determined. For the arc path in Fig. 2(a), a cross section $3 \mathrm{~m}$ away from the blade tip is taken as research subject. Since the experimental results show that the right web does not crack, only the right side of the right web is considered as arc area. That is called model I. For the arc path in Fig. 2(b), a cross section $2 \mathrm{~m}$ away from the blade tip is taken as research subject. The experimental results show that only the right web bursts and the left web have no structural damage, so only the right side of the left web is considered as arc area. Due to the blocking effect of the right web, a portion left area is a non-arc area. That is called model II. For the arc path in Fig. 2(c), a section $1 \mathrm{~m}$ away from the blade tip is taken as research subject, which is called model III. The red line in Table 1 indicates the arc plasma area, and the blue area is the calculation area.

Tab. 1 Geometry models adopted in the simulation

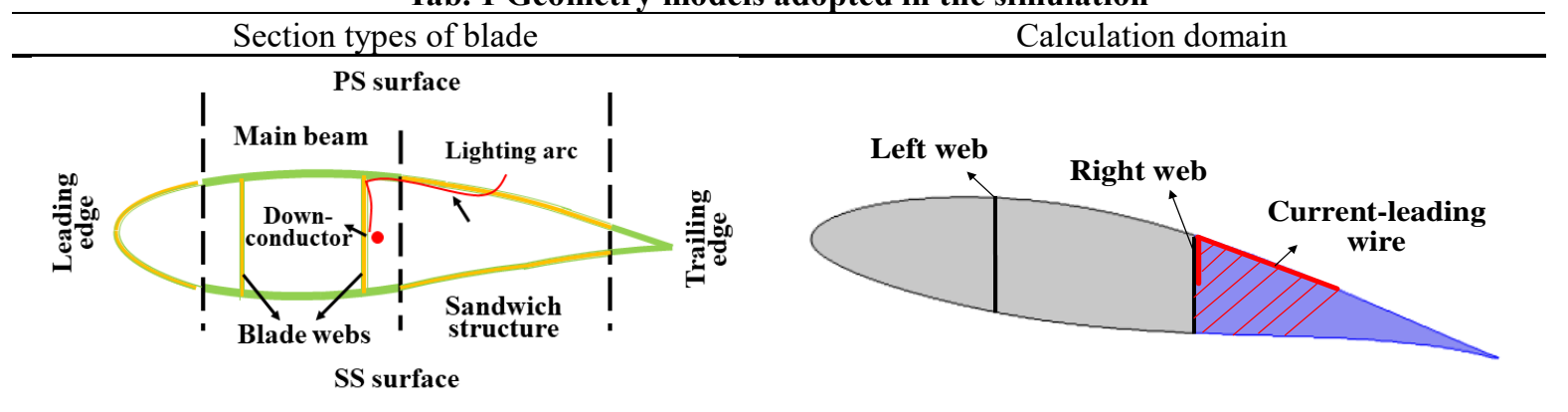

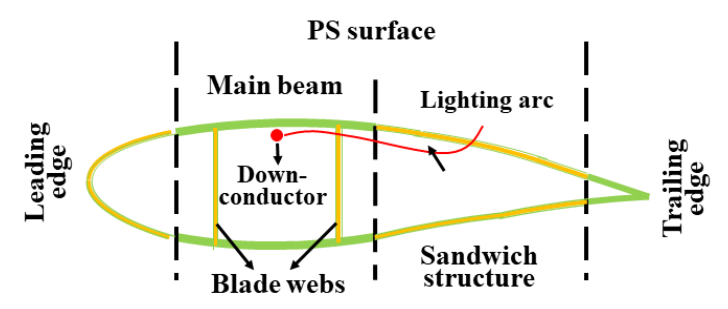

SS surface

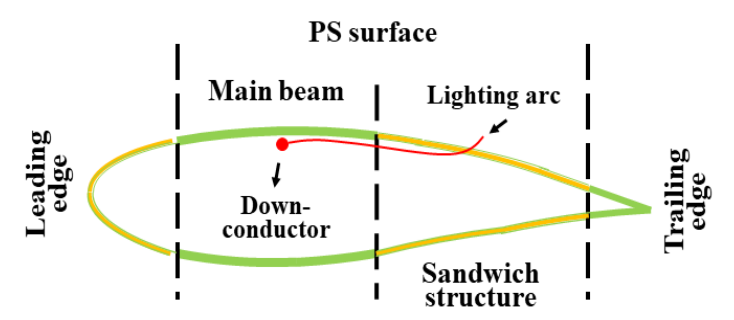

SS surface
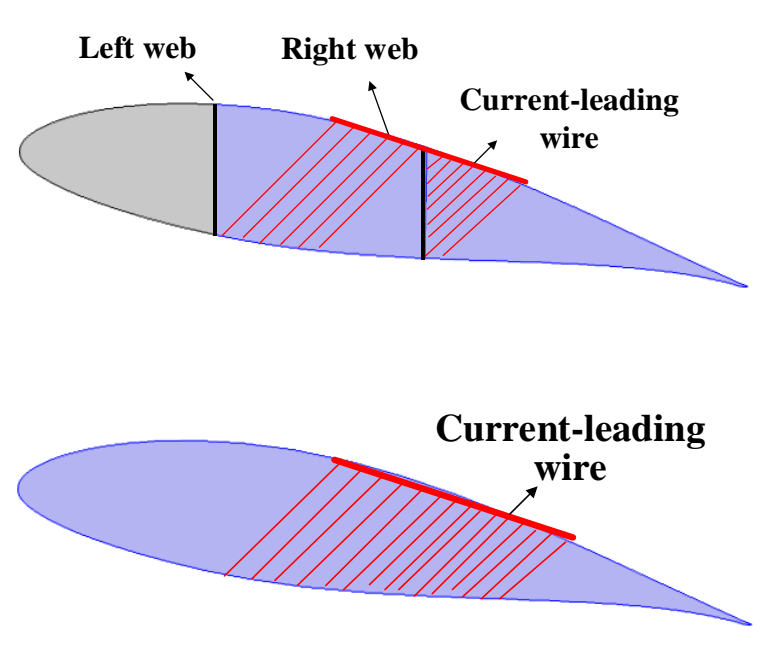


\subsection{Arc plasma model}

The arc path is assumed as a straight line. For the model I, the real arc path is a polyline. each segment is solved separately and added together. In the arc area shown by the red line in Table I, for the following two reasons, it is assumed that the direction of the current density $\mathbf{J}$ is parallel to the current-leading wire.

On the one hand, the current density is formed by the movement of the arc plasma. The average velocity of the airflow in the direction of vertical to the current-leading wire is $1020 \mathrm{~m} / \mathrm{s}$, and the longest distance from the PS surface to the SS surface is about $0.3 \mathrm{~m}$. The time is $0.29 \mathrm{~ms}$ required for the diffusion of the airflow from the current-leading wire to SS surface. Hence, it is considered that the diffusion of the arc plasma pushed by the airflow is instantaneous in the direction of vertical to the current-leading wire, and the current density $\boldsymbol{J}$ does not have component in this direction. On the other hand, in the experiment, the current flows in the direction of the current-leading wire, therefore the most arc plasma generated by the current moves in the same direction. The current density is formed by the movement of the arc plasma, so the direction of the current density $\boldsymbol{J}$ is parallel to the current-leading wire.

The assumption of $\boldsymbol{J}$ is as follows: it is the maximum at the current-leading wire, set as $\boldsymbol{J}_{\max }$, and decreases exponentially downward, set as 0 at the SS of the blade. Since the exponential function cannot reach 0 , a small number of 0.1 is used to instead. Based on the assumptions above, the current density can be obtained by equation (5) and equation (6).

$$
\begin{gathered}
\int_{0}^{L_{s s}} J\left(r_{1}\right) d l=I, \\
I(t)= \begin{cases}I_{\text {peak }} \frac{t}{t_{\mathrm{m}}} & t<t_{\mathrm{m}} \\
I_{\text {peak }} \exp \left[-\alpha\left(t-t_{\mathrm{m}}\right)\right] & t>t_{\mathrm{m}}\end{cases}
\end{gathered}
$$

$L_{\mathrm{ss}}$ is the distance from the SS surface to current-leading wire, and $r_{1}$ is the vertical distance from any point in the calculation domain to the current-leading wire. $a$ is a constant. $I$ is the injection current, the value of which is obtained by equation (7). $I_{\text {peak }}$ is the peak value of impulse current, being $30 \mathrm{kA}$ and $150 \mathrm{kA}, t_{\mathrm{m}}$ is the peak time of impulse current, being $25 \mu$ s according to experimental data, $\alpha$ is referred to attenuation constant, being 0.003 .

\subsection{Electromagnetic field equation}

The arc is a fluid with electrical conductivity, and electromagnetic field inside it would affect the characteristics of the fluid, such as pressure and temperature. In order to calculate the Joule heat and the Lorentz force, it is necessary to figure out the distribution of the electric field and magnetic field.

According to Ohm law, the electric field strength $\boldsymbol{E}$ is obtained by equation (8). The distribution of magnetic induction $\boldsymbol{B}$ can be obtained according to Biot-Savart's law shown as equation (9).

$$
\begin{gathered}
\mathbf{E}=\mathbf{J} / \sigma, \\
\mathbf{B}=\int \frac{\mu_{0} I(t)}{4 \pi} \cdot \frac{d \mathbf{l} \times \mathbf{e}_{r_{2}}}{r_{2}^{2}}+\int \frac{\mu_{0} I^{\prime}(t)}{4 \pi} \cdot \frac{d \mathbf{l} \times \mathbf{e}_{r_{2}}}{c r_{2}},
\end{gathered}
$$

Where, $\sigma$ is the conductivity, $\mu_{0}$ is the magnetic permeability, $\mathrm{d} \boldsymbol{l}$ is the line integral element, $\boldsymbol{e}_{\mathrm{r} 2}$ is the unit direction vector between the current element and the point to be calculated, $r_{2}$ is the distance between the point to be determined and the direction vector, $I^{\prime}(t)$ is derivative of the current value versus time, $\mathrm{c}$ is the speed of light.

\section{Simulation results and discussion}

In this section, we figure out temporal and spatial variation of temperature and pressure and the mechanism of blade damage under lightning arc is revealed. Furthermore, $I_{\text {peak }}=30 \mathrm{kA}$ is selected to study the damage of lightning arc to the blade. Based on the data of temperature at point $\mathrm{A}$ and pressure at point $\mathrm{B}$, we propose some suggestions to enhance the ability of lighting protection for the blade.

\subsection{Case study $\left(I_{\text {peak }}=150 \mathrm{kA}\right)$}

In order to verify the rationality of the simulation model, results when $I_{\text {peak }}=150 \mathrm{kA}$ are selected to compare with the experimental phenomena. The temperature at point A (arc ignited point) and the pressure at point B (trailing edge) in the Fig. 9 are analyzed.

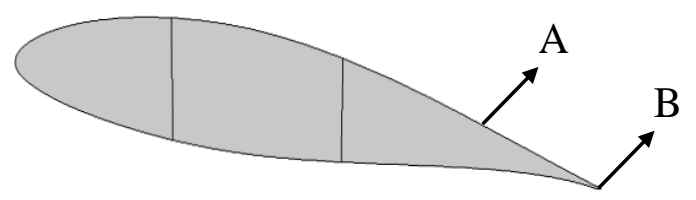

Fig. 9 Simulation analysis diagram (A represents arc ignited point and $B$ represents the trailing edge of the blade) 


\subsubsection{Temperature analysis at point $A$}

The main material of the blade surface is epoxy resin. Epoxy resin would be destroyed under high temperature and decomposed into small molecular products. Chatterjee et al. found that the pyrolysis temperature was concentrated at hundreds of kelvins for different types of epoxy material [22]. The damage to the epoxy material would be more severe if the temperature is higher.

Fig. 10 shows the temperature of point A for model I. As can be seen from the figure, the temperature at point A increases rapidly and then decreases after reaching the first peak value. It starts increasing again until reaching the second peak value. Finally, it fluctuates around $1549 \mathrm{~K}$ until stabilizes. This value $(1549 \mathrm{~K})$ is much larger than pyrolysis temperature for epoxy material, indicating that the blade would be carbonized.

From the perspective of heat conduction, we analyze the reasons for the above phenomena. Due to the narrow space at the junction of the right web and PS surface, heat flow is easy to accumulate, so the high temperature area appears here firstly. The heat starts to convect in the blade cavity. Then it is conducted from the region with high temperature to the region with low temperature, at the same time, the high temperature region gradually spreads toward the trailing edge along the PS surface. For this time, the temperature of point A increases rapidly. However, lightning has a transient effect and short duration. After the lightning current tends to be 0 , There is no new heat to be generated. The original heat inside the blade diffuses from PS surface with high temperature to SS surface with low temperature. For this time, the temperature of point A decreases. On the other hand, the heat generated by the lighting arc on the right web diffuses toward the trailing edge. The two diffusion interact to form a high temperature region. Furthermore, the heat spreads around, and the temperature at point A increases again. Finally, the heat is evenly distributed, the temperature of point A tends to be stable.

The above phenomenon is analyzed combining with the dynamic image shown in Fig. 11. At $0.2 \mathrm{~ms}$, the high temperature area appears at the boundary between the right web and the PS surface. From $0.2 \mathrm{~ms}$ to $0.5 \mathrm{~ms}$, the high temperature area diffuses to the trailing edge of the blade along PS surface. At this time, the temperature of the point A would suddenly increase, reaching the first peak value in Fig. 10. From $0.5 \mathrm{~ms}$ to $2 \mathrm{~ms}$, the high temperature area gradually moves downward, and the temperature of the point A drops until reaching the minimum value in Fig. 10. From 2 ms to 5 $\mathrm{ms}$, the high temperature area spreads inside the blade chamber, and the temperature of the point A increases again until around $1549 \mathrm{~K}$. After $5 \mathrm{~ms}$, the temperature in the blade chamber tends to be a same value and reaches a stable state, which is called stable temperature.

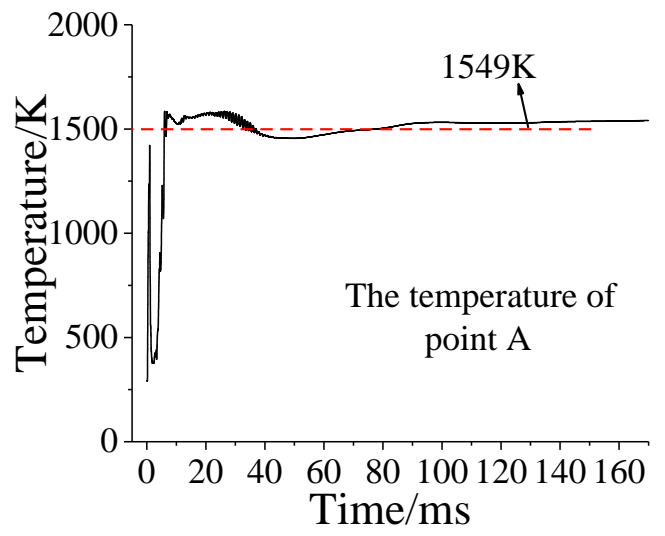

Fig. 10 Variation of the temperature of the point A with time

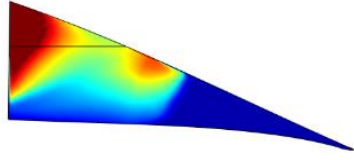

$0.2 \mathrm{~ms}$

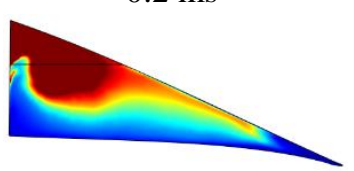

$0.6 \mathrm{~ms}$

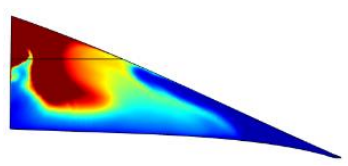

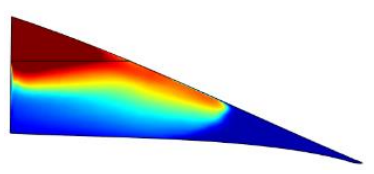

$0.3 \mathrm{~ms}$

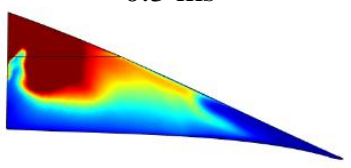

$0.7 \mathrm{~ms}$

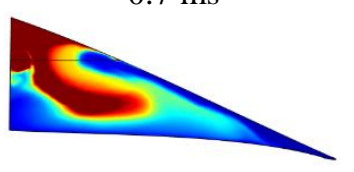

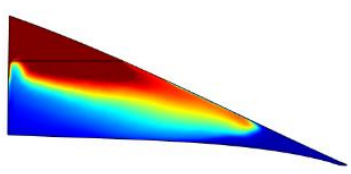

$0.4 \mathrm{~ms}$

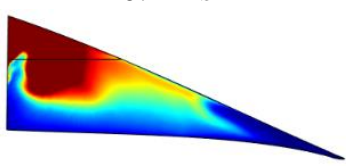

$0.8 \mathrm{~ms}$

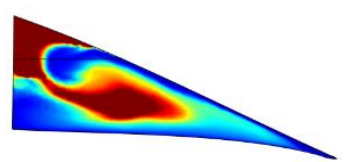

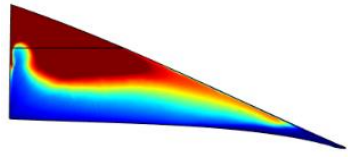

$0.5 \mathrm{~ms}$

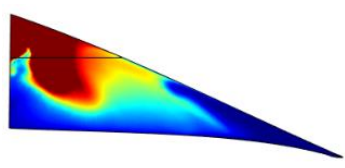

$0.9 \mathrm{~ms}$

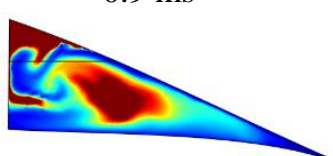




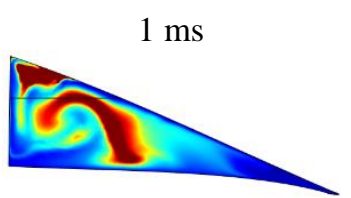

$1.8 \mathrm{~ms}$

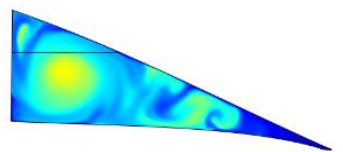

$4 \mathrm{~ms}$

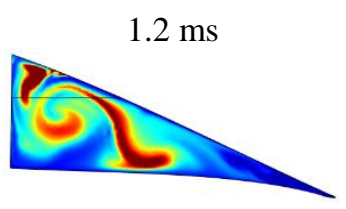

$2 \mathrm{~ms}$

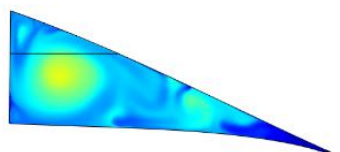

$5 \mathrm{~ms}$

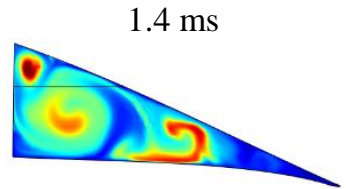

$2.5 \mathrm{~ms}$

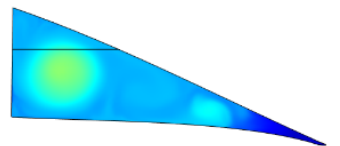

$10 \mathrm{~ms}$

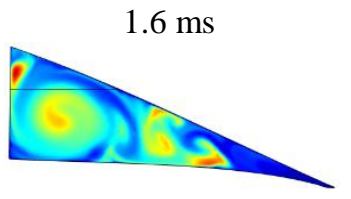

$3 \mathrm{~ms}$

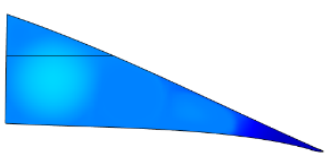

$50 \mathrm{~ms}$

\section{\begin{tabular}{llllllllll}
$\times 10^{3}$ & 4.5 & 4 & 3.5 & 3 & 2.5 & 2 & 1.5 & 1 & 0.5 \\
\hline
\end{tabular} \\ Temperature(K) \\ Fig. 11 Temperature diffusion process inside the blade}

For model II and model III, the change of point A is similar to that in Fig. 10. The stable temperature for all models in simulation and the length of material carbonization near arc ignited point in experiment are listed in Table 2.

Tab. 2 Stable temperature in the simulation and length of carbonization in the experiment

\begin{tabular}{ccc} 
& Simulation Results & Experiment Results \\
\hline \multirow{2}{*}{ Type } & Stable Temperature & Length of Material Carbonization \\
Model I & $(\mathrm{K})$ & $(\mathrm{cm})$ \\
Model II & 1549 & 33 \\
Model III & 2603 & 52 \\
\hline
\end{tabular}

By comparing the stable temperature of point $\mathrm{A}$ and the carbonization length near the arc ignited point, it is found that they have a positive correlation. The higher the temperature in the simulation, the more serious carbonization of the material in experiment, which verifies the correctness of the simulation results.

\subsubsection{Pressure analysis at point $B$}

At the trailing edge of the blade, the PS surface and SS surface are glued by an epoxy adhesive, as shown in Fig. 12. The large impulse current generates high-speed airflow, and the pressure act on the PS and SS surface, thereby causing damage to the epoxy resin adhesive. This kind of damage is called T-peeling, as shown in Fig. 13.

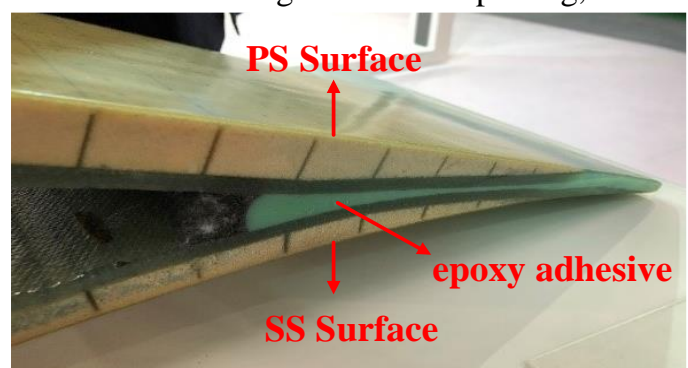

Fig. 12 Blade trailing edge

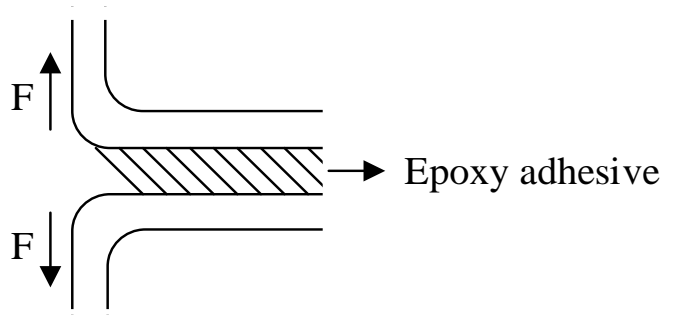

Fig. 13 A diagram of T-peeling

The T-peel strength refers the ability that two bonded samples resist to be peeled. The T-peel strength of epoxy resin ranges from 3 to $11 \mathrm{~N} / \mathrm{mm}$. The width of the trailing edge epoxy adhesive is $2.1 \mathrm{~cm}$ in the experiment. According to this, T-peel strength of blade trailing edge is calculated. As shown in the equation (10), the maximum pressure that the trailing edge can withstand is $231 \mathrm{~N}$.

$$
21 \mathrm{~mm} \times 11 \mathrm{~N} / \mathrm{mm}=231 \mathrm{~N}
$$


Fig. 14 shows the pressure of point B for model I. Firstly, the pressure of point B quickly reaches the peak value, then shows a trend of fluctuation and the amplitude decrease with time, finally reaches a stable value. In Fig. 14, the maximum pressure at the trailing edge is $2.03 \times 10^{7} \mathrm{~Pa}$. According to a standard "Adhesives, T-peel strength test method for a flexibleto-flexible test specimen assembly" published by China Chemical Industry Association [23], a $2.5 \mathrm{~cm} \times 5 \mathrm{~cm}$ facet is taken on the trailing edge of the blade in Fig. 15. As shown in equation (11), the pressure of the trailing edge is $25375 \mathrm{~N}$. This value is much larger than $231 \mathrm{~N}$, indicating that the trailing edge of the blade would crack.

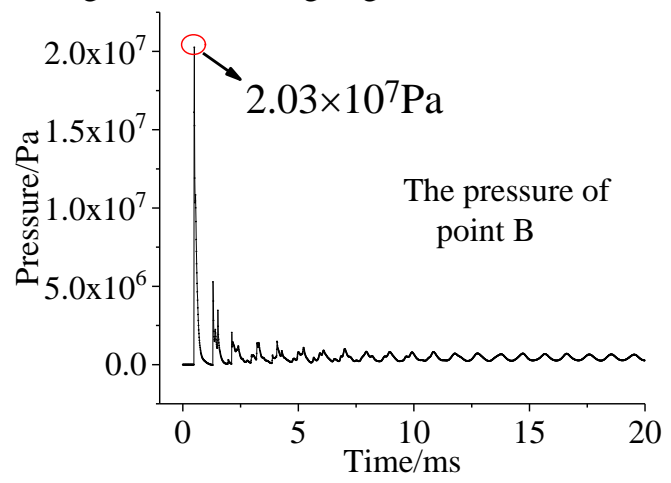

Fig. 14 Variation of the pressure of the point $B$ with time

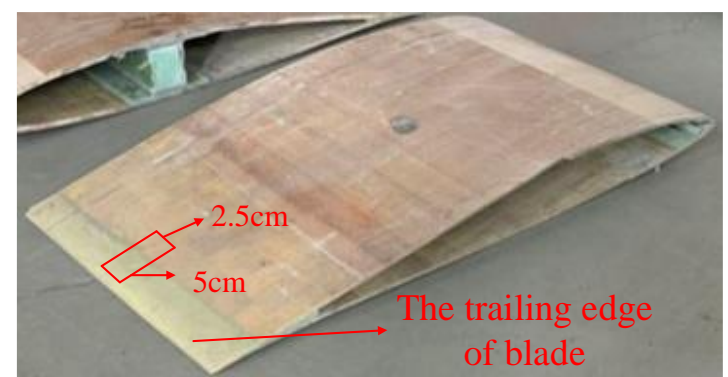

Fig. 15 A $2.5 \mathrm{~cm} \times 5 \mathrm{~cm}$ facet on the trailing edge of the blade

$$
0.05 m \times 0.025 m \times 2.03 \times 10^{7} \mathrm{~Pa}=25375 N,
$$

The above phenomenon is analyzed combining with the dynamic image shown in Fig. 16. The area with high pressure first appears at the junction of the right web and the PS surface, and then the airflow diffuses downward. After diffusing to the junction of the right web and the SS surface, the airflow diffuses towards the trailing edge and the pressure of point B increases rapidly. After the pressure of point B reaches the first peak value shown in Fig. 14, the airflow diffuses between the trailing edge and the right web back and forth.

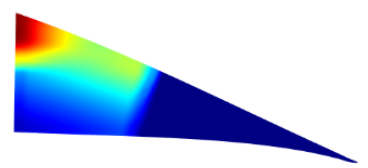

$0.05 \mathrm{~ms}$

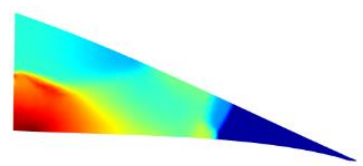

$0.25 \mathrm{~ms}$

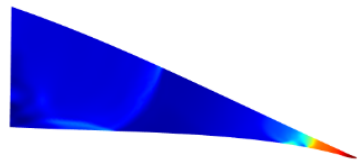

$0.6 \mathrm{~ms}$

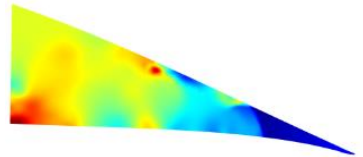

$1 \mathrm{~ms}$

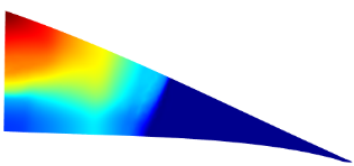

$0.1 \mathrm{~ms}$

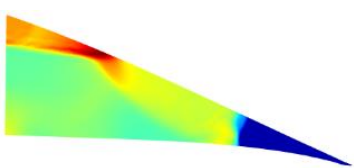

$0.3 \mathrm{~ms}$

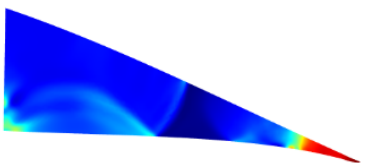

$0.75 \mathrm{~ms}$

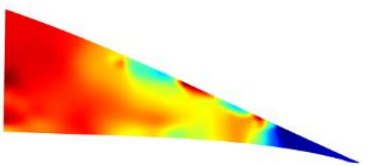

$1.1 \mathrm{~ms}$

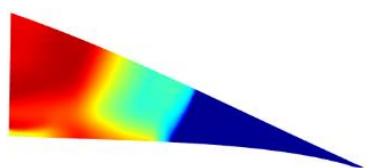

$0.15 \mathrm{~ms}$

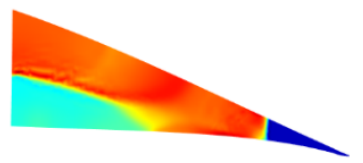

$0.35 \mathrm{~ms}$

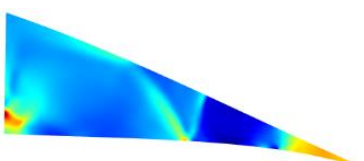

$0.8 \mathrm{~ms}$

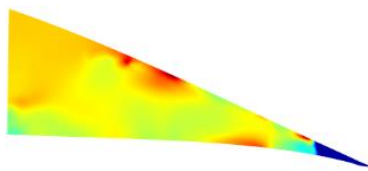

$1.2 \mathrm{~ms}$

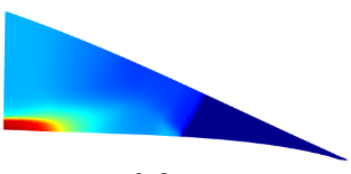

$0.2 \mathrm{~ms}$

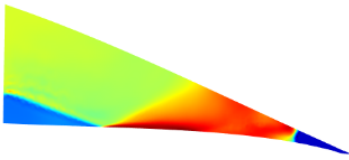

$0.4 \mathrm{~ms}$

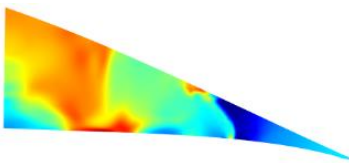

$0.9 \mathrm{~ms}$

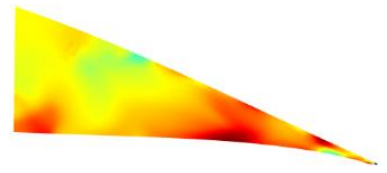

$1.3 \mathrm{~ms}$ 


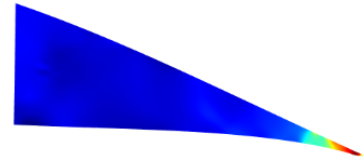

$1.4 \mathrm{~ms}$

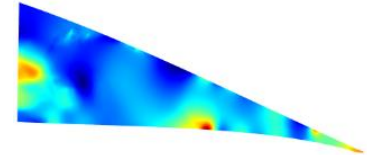

$1.5 \mathrm{~ms}$

\section{Pressure increases in this direction}

Fig. 16 Pressure diffusion process inside the blade

For model II and model III, the pressure change of point B is similar to that in Fig. 14. The maximum pressure for all models in simulation and the crack length of trailing edge in experiment are listed in Table 3. In particular, the space of blade tip is narrow, which is easy to cause high pressure accumulation. The length of the crack in the direction of blade tip is easily affected by its narrow structure, thus it is not counted in Table 3 . The length of crack in the Table 3 is the length of the crack in the direction of the blade root starting from the arc ignited point.

Tab. 3 Maximum pressure in the simulation and length of crack in the experiment

\begin{tabular}{ccc} 
& Simulation Results & Experiment Results \\
\hline Type & Maximum Pressure & $\begin{array}{c}\text { Length of Crack } \\
\left(\times 10^{6} \mathrm{~Pa}\right)\end{array}$ \\
Model I & 20.3 & 151 \\
Model II & 16.4 & 82 \\
Model III & 18.0 & 102 \\
\hline
\end{tabular}

By comparing the maximum pressure of point B and the crack length of trailing edge, it is found that they have a positive correlation. The higher the pressure in the simulation, the lager the crack length of the trailing edge in the experiment, which verifies the correctness of the simulation.

The peak value of lightning current is $150 \mathrm{kA}$ in above research, however, the probability of $I_{\text {peak }}=150 \mathrm{kA}$ is small. Orville et al. observed the lightning phenomenon in the United States from 1989 to 1999 and found that the median of the $I_{\text {peak }}$ was around $30 \mathrm{kA}$ [24]. Therefore, $I_{\text {peak }}=30 \mathrm{kA}$ is selected to study the damage of lightning arc to the blade. In the following paper, the point $\mathrm{A}$ and $\mathrm{B}$ represent same meaning as that in Fig. 7.

\subsection{Case study $\left(I_{\text {peak }}=30 \mathrm{kA}\right)$}

The arc paths shown in the top and bottom picture in Table 1 represent a same kind of layout of down-conductor in the blade, so they are referred as arc path I in next study. The arcing path in the middle picture of Table 1 is called the arcing path II. In addition, a section $5 \mathrm{~m}$ away from the tip of the blade is included in the study.

\subsubsection{Temperature analysis at point $A$}

Comparing the temperature change of point A for different position of arc ignited points and arc paths, it is found that their peak values are concentrated at 430-500 K, and their trends are similar. Fig. 17 shows the temperature with time of point $\mathrm{A}$ for arc path I and the arc ignited point is $3 \mathrm{~m}$ away from blade tip. Temperature of point $\mathrm{A}$ increases rapidly to a peak value of $472 \mathrm{~K}$, and then begins to slowly decrease. The maximum temperature is lower than the temperature required for the carbonization of the blade material. But the heat distortion temperature of the adhesive between the web and surface is $338 \mathrm{~K}$ recommended by Germanischer Lloyd company [25]. At this time, the failure of the adhesive should be noticed.

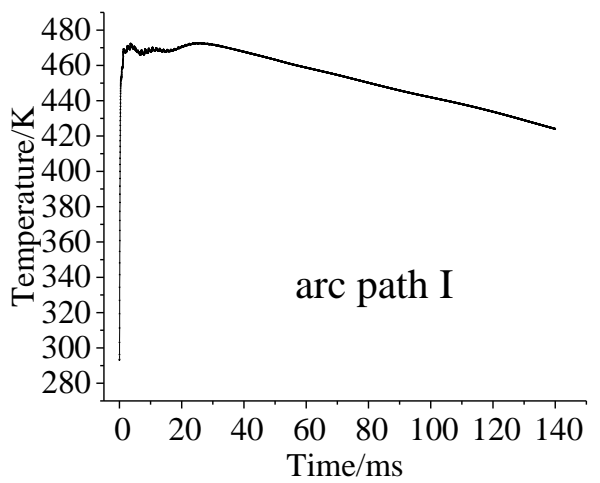

Fig. 17 Variation of the temperature of the point $A$ with time

\subsubsection{Pressure analysis at point $B$}

The pressure of point B is analyzed for different position of arc ignited points and arc paths, as shown in Fig. 18. According to equation (11), the maximum pressure is put into equation (11) and calculated. Results $(125-268 \mathrm{~N})$ are close to the maximum pressure of the trailing edge can withstand $(231 \mathrm{~N})$. Hence, it is hard to judge whether the trailing edge of the blade would crack. When the position of arc ignited is the same point in Fig. 18, the maximum pressure for the arc path I is greater than the arc path II, and the closer the arc ignited point to the tip, the larger the maximum pressure is. The above results indicate that when the lightning strike point is close to the tip of the blade, the risk of damage to the blade would increase. From the view of lightning protection, it is recommended that the layout of the down-conductor in the blade adopts the form shown in the middle picture of Table 1. 


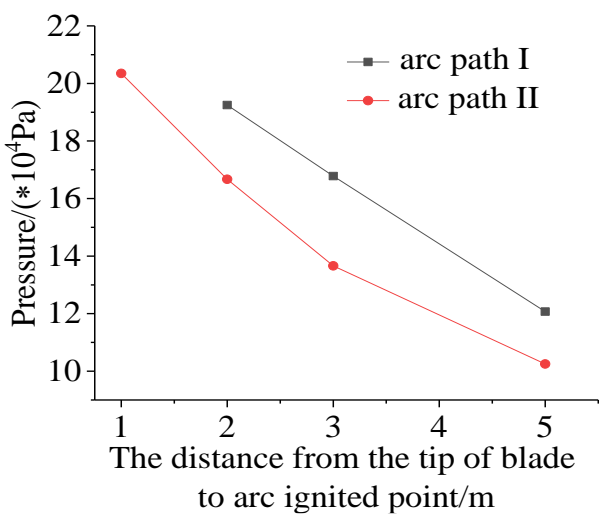

Fig. 18 Maximum pressure for different arc ignited positions and arc paths

The number of the peak value is figured out (red circles in the Fig. 19) from $0 \mathrm{~ms}$ to $30 \mathrm{~ms}$ for different position of arc ignited points when arc path I is adopt, as shown in Table 4. It is found that the trailing edge of the blade would suffer more impacts if the arc ignited point is closer to the tip of blade. In Ref. 26, they found that the dynamic compressive strength of the material would gradually decrease if the number of the maximum value of the pressure increases, which might cause material damage. From the perspective of strengthening the lightning resistance of the blade, the blade manufacturer should improve the toughness of the epoxy adhesive material to resist multiple consecutive impacts.

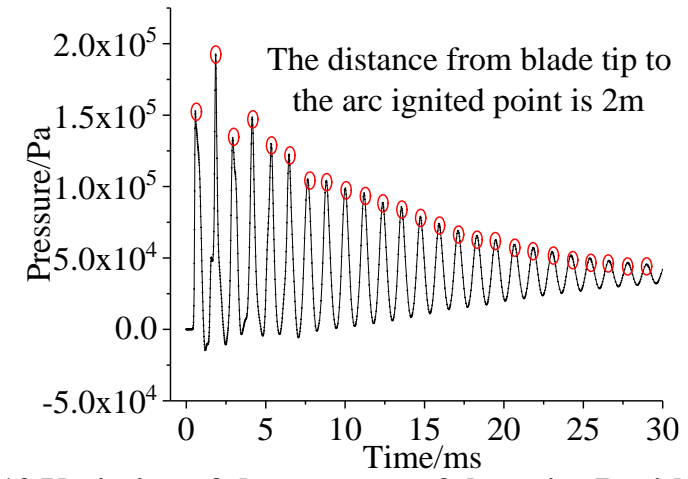

Fig. 19 Variation of the pressure of the point $B$ with time

Tab. 4 The number of the peak value of the point $B$ pressure in the simulation

\begin{tabular}{cc}
\hline $\begin{array}{c}\text { The distance from the tip of blade } \\
\text { to arc ignited point }\end{array}$ & $\begin{array}{c}\text { The number of the peak value } \\
\text { of the point B pressure }\end{array}$ \\
\hline $3 \mathrm{~m}$ & 13 \\
$2 \mathrm{~m}$ & 18 \\
$1 \mathrm{~m}$ & 25 \\
\hline
\end{tabular}

\section{Conclusion}

Experiment and simulation were conducted to study the damage mechanism of wind turbine blade under the impact of lightning induced arc. In this paper, the following conclusions have been drawn.

1. In the experiment, the blade tends to crack from the position of the trailing edge near the arc attachment point and the crack extends in the direction of the blade root and tip. The length of carbonization damage caused by high temperature of arc is much smaller than the crack length due to the airflow impact. When the down-conductor is placed on the main beam, carbonization damage distributes in the area between the left web and the trailing edge. When placed on the right web, it distributes between the right web and the trailing edge.

2. In the simulation, the temperature of the arc ignited point increases to the peak value and then decreases rapidly and then, it increases to the maximum and tends to stabilize. The high temperature inside the blade region diffuses from the boundary between the pressure surface and the right web to the trailing edge. The pressure of trailing edge increases to the maximum and then oscillates to decrease. The airflow inside the blade continuously oscillates between the right web and the trailing edge.

3. It is found that the temperature of the arc ignited point has a positive relationship with the length of the material carbonization in the experiment, so does the pressure of trailing edge with the length of the trailing edge crack. The above results verify the rationality of the simulation model.

4. From the perspective of lightning protection, it is recommended that the down-conductor is set between on the main beam and improve the toughness of the epoxy adhesive material to resist multiple consecutive impacts. 


\section{Acknowledgment}

This work is supported by National Natural Science Foundation of China (51420105011).

\section{Reference}

${ }^{1}$ J. Yao, and Y. Zhu, "Research on the main factors affecting the development and utilization of wind energy in Jilin Province, China," Journal of Renewable and Sustainable Energy, 11, 015904(2019).

${ }^{2}$ A. C. Garolera, S. F. Madsen, M. Nissim, J. D. Myers, and J. Holboell, "Lightning damage to wind turbine blades from wind farms in the US," IEEE Trans. Power Deliv. 31(3), 1043-1049(2016).

${ }^{3}$ S. Yokoyama, “Lightning protection of wind turbine blades,” Electr. Power Syst. Res. 94, 3-9(2013).

${ }^{4}$ A. C. Garolera, J. Holboell, and S. F. Madsen, "Lightning attachment to wind turbine surfaces affected by internal blade conditions," International Conference on Lightning Protection (ICLP), pp. 1-7(2012).

${ }^{5}$ Q. Li, Y. Ma, Z. Guo, H. Ren, G. Wang, W. Arif, Z. Fang, and W. H. Siew, "The lightning striking probability for offshore wind turbine blade with salt fog contamination,” J. Appl. Phys. 122(7), 073301(2017).

${ }^{6}$ Y. Wang, L. Qu, T. Si, Y. Ni, J. Xu, and X. Wen, "Experimental study of rotating wind turbine breakdown characteristics in large scale air gaps," Plasma Science Technol. 19(6), 064016(2017).

${ }^{7}$ S. F. Madsen, J. Holb, M. Henriksen, and K. Bertelsen. “New test method for evaluating the lightning protection system on wind turbine blades," 28th International Conference on Lightning Protection (ICLP), 2016.

${ }^{8}$ T. Ogasawara, Y. Hirano, and A. Yoshimura, “Coupled thermal-electrical analysis for carbon fiber/epoxy composites exposed to simulated lightning current," Compos. Part A: Appl. Science Manuf. 41(8), 973-981(2010).

${ }^{9}$ L. Zhang, L. Jiang, T. Zhao, and L. Zou, "Microcosmic Mechanism Investigation on Lightning Arc Damage of Wind Turbine Blades Based on Molecular Reaction Dynamics and Impact Current Experiment,” Energies. 10(12), 2010(2017).

${ }^{10} \mathrm{Y}$. Wang and O. I. Zhupanska, "Modeling of thermal response and ablation in laminated glass fiber reinforced polymer matrix composites due to lightning strike,” Appl. Math. Model. 53, 118-131(2018).

${ }^{11}$ T. M. Dhanya and C. S. Yerramalli, "Lightning strike effect on carbon fiber reinforced composites-effect of copper mesh protection,” Mater. Today Commun. 16, 124-134(2018).

${ }^{12}$ D. Romero, J. A. Rey, J. Montanya, R. Horta, and G. Tobella, "Investigation of potential distribution on a CFRP coupon under impulse current. Test results and FDTD simulation,” International Conference on Lightning Protection (ICLP), 2016.

${ }^{13}$ H. Kawakami and P. Feraboli, "Lightning strike damage resistance and tolerance of scarf-repaired mesh-protected carbon fiber composites," Compos. Part A, 42(9), 1247-1262(2011).

${ }^{14}$ Y. Goda, S. Tanaka, and T. Ohtaka, “Arc Tests of Wind Turbine Blades Simulating High Energy Lightning Strikes,” International Conference on Lightning Protection (ICLP), 2008.

${ }^{15}$ K. Inoue, Y. Korematsu, and N. Nakamura, "Study on damage-mechanism of wind turbine blades by lightning strike," International Conference on Lightning Protection (ICLP), 2006.

${ }^{16} \mathrm{P}$. Xu, Z. Yang, W. Wei, G. Gao, and G. Wu, "Modeling and simulation of arc and contact wire molten pool behavior during pantograph lowering process," Aip Adv. 8(11), 115008(2018).

${ }^{17}$ H. Shi, X. Zou, and X. Wang, "Measuring the dynamic polarizability of tungsten atom via electrical wire explosion in vacuum," Phys. Plasmas, 25(2), 022707(2018). 
$341{ }^{18}$ M. Rong, M. Li, Y. Wu, F. Yang, Y. Wu, W. Liu, Y. Li, and Z. Chen, “3-D MHD Modeling of Internal Fault Arc in a Closed Container,” IEEE Trans. 342 Power Deliv. 32(3), 1220-1227(2017).

$343{ }^{19} \mathrm{Q}$. Li, and J. D. Yan, “Computational Investigation of the Magnetic-Field Distribution in a 145-kV/40-kA Rotary-Arc Circuit Breaker,” IEEE Trans. 344 Power Deliv. 21(1), 135-141(2006).

$345{ }^{20}$ Q. Sun, H. Liu, F. Wang, S. Chen, and Y. Zhai, "Parameter estimation of extended free-burning electric arc within 1 kA," Phys. Plasmas, 25(5), 346 052117(2018).

$347{ }^{21}$ F. Karetta and M. Lindmayer, "Simulation of the gasdynamic and electromagnetic processes in low voltage switching arcs," IEEE Trans. Compon. 348 Packag. Manuf. Technol. Part A, 21(1), 96-103(1998).

34922 A. Chatterjee and M. S. Islam, “Fabrication and characterization of $\mathrm{TiO}_{2}$-epoxy nanocomposite," Mater. Sci. Eng. A, 487(1-2), 574-585(2008).

35023 “'Adhesives, T peel strength test method for a flexible test specimen assembly," Standards Press of China, Beijing, 1995.

$351{ }^{24}$ R. E. Orville and G. R. Huffines, “Cloud-to-Ground Lightning in the United States: NLDN Results in the First Decade, 1989-98,” Mon. Weather. 352 Rev. 129(5), 1179-1193(2001).

35325 "Guideline for the Certification of Wind Turbines," Germanischer Lloyd, German, 2012.

$354{ }^{26}$ M. Z. N. Khan, Y. Hao, H. Hao, and F. U. A. Shaikh, "Experimental evaluation of quasi-static and dynamic compressive properties of ambient-cured high-strength plain and fiber reinforced geopolymer composites," Constr. Build. Mater. 166, 482-499(2018). 